Report

\title{
Weekly low-dose mitoxantrone plus doxorubicin as second-line chemotherapy for advanced breast cancer
}

\author{
M. Bontenbal,' A.S.Th. Planting,' C.J. Rodenburg,' A. Dees,' J. Verweij,' C.C.M. Bartels,' \\ J. Alexieva-Figusch,' W.L.J. van Putten² and J.G.M. Klijn' \\ 'Department of Medical Oncology, and ${ }^{2}$ Department of Statistics, Rotterdam Cancer Institute \\ (Dr Daniel den Hoed Cancer Center), Rotterdam, The Netherlands
}

Key words: breast cancer, chemotherapy, doxorubicin, mitoxantrone

\section{Summary}

Weekly low dose mitoxantrone $\left(3 \mathrm{mg} / \mathrm{m}^{2}\right)$ plus doxorubicin $\left(8 \mathrm{mg} / \mathrm{m}^{2}\right)$ was administered as second-line chemotherapy to 33 patients with advanced breast cancer. Four out of 28 evaluable patients (14\%) obtained a partial response with a median duration of 34 weeks (range $18-67^{+}$weeks), while 8 patients (29\%) showed stable disease with a median duration of 28 weeks (range $11^{+}-60$ weeks). Gastrointestinal toxicity and alopecia were mild. Grade II and III leukopenia occurred in $63 \%$ of the courses without serious infectious disease. Four patients experienced an asymptomatic drop of 16-20\% in the left ventricular ejection fraction (LVEF) after relatively low cumulative doses of each drug, and one patient with a history of pericarditis carcinomatosa and mediastinal irradiation developed a heart failure. In conclusion, this second-line combination treat-ment had moderate activity in breast cancer and caused only few subjective side effects, especially with respect to gastrointestinal symptoms.

\section{Introduction}

Combination chemotherapy appears to be more effective than single agent therapy in inducing responses in disseminated breast cancer. First-line treatment with cyclophosphamide, methotrexate, and fluorouracil (CMF) induces a response in about $40-50 \%$ of the patients with a median duration of response of less than a year [1]. Second-line chemotherapy in CMF-refractory patients often consists of single agent treatment with ( $4^{\prime}$-epi-) doxorubicin or mitoxantrone in a 3-weekly highdose schedule. However, only about $20-30 \%$ of these patients achieve a remission, frequently of short duration, while toxicity is often considerable especially by treatment with anthracyclines [2-4].

When (4'-epi-)doxorubicin or mitoxantrone are administered in low dose schedules every week or twice a month, the drugs can still be active, with remission rates of about $30 \%(0-59 \%)$ in patients with advanced breast cancer [5-22]. Gastrointestinal toxicity and alopecia are significantly less with these low-dose schedules.

Cardiotoxicity is a major problem of long-term ( $4^{\prime}$-epi-)doxorubicin treatment, while mitoxantrone occasionally produces such toxicity. Doxorubicin cardiotoxicity is probably induced by the intracellular formation of free radicals and stimulation of membrane lipid peroxidation in the heart 
muscle cells [23]. In experimental studies with hearts of rats, evidence was found that mitoxantrone did not form free radicals, and had a strong inhibitory effect on the lipid peroxidation [24, 25]. In addition mitoxantrone was found to cause a concentration-dependent inhibition of doxorubicinstimulated lipid peroxidation in liver microsomes of rabbits [26]. These data suggest that mitoxantrone might have an inhibitory effect on the occurrence of doxorubicin-induced cardiotoxicity. Furthermore, low-dose schedules of doxorubicin seem to produce less cardiotoxicity $[5,6,27,28]$. In view of these data it appeared attractive to combine doxorubicin and mitoxantrone at weekly dosages. Therefore, we initiated a phase II study with the combination of low doses of doxorubicin and mitoxantrone in a weekly schedule as second-line chemotherapy for patients with advanced breast cancer.

\section{Patients and methods}

Eligibility criteria of the protocol included: patients with measurable or evaluable lesions, age less than 80 years, World Health Organization (WHO) performance score 2 or less, life expectancy of more than 2 months, serum bilirubin less than $40 \mu \mathrm{mol} / \mathrm{l}, \mathrm{WBC}$ above $3.0 \times 10^{9} / \mathrm{l}$, platelets above $100 \times 10^{\%} / 1$, no prior therapy with anthracyclines or mitoxantrone. Patients with a history of recent cardiac disease or with metastases in the central nervous system were excluded. Metastatic disease of all patients had to be resistant to previous endocrine therapy and to first-line chemotherapy with CMF (cyclophosphamide, methotrexate, and fluorouracil). The protocol (DDHK 88-18) was approved by 2 different committees, both a protocol review and a medical ethics committee. All patients gave oral informed consent before entering the study.

On-study evaluation consisted of medical history, physical examination, tumor measurements, complete blood count ( $\mathrm{Hb}$, WBC, platelets), automated blood chemistry, left ventricular ejection fraction (LVEF, using radionuclide multigated analysis with intervals of initially 12 , subsequently
8 or 4 weeks), bone scan, bone and chest x-rays, and liver CT-scan (in case of liver metastases).

Treatment consisted of mitoxantrone $3 \mathrm{mg} / \mathrm{m}^{2}$ plus doxorubicin $8 \mathrm{mg} / \mathrm{m}^{2}$ as weekly sequential intravenous injections via a running infusion with physiologic saline during a few minutes. Responses were defined according to WHO criteria. Duration of partial response was measured from initiation of therapy until time of tumor progression. Drug toxicity was also evaluated according to WHO criteria.

\section{Results}

Patient characteristics are indicated in Table 1. Thirty-three patients entered the study. Twentyeight patients were evaluable for response and toxicity. Five patients were not evaluable because of early withdrawal or lack of response evaluation (within the first 8 weeks). Reasons to stop the treatment were: patient refusal (2), radiation therapy for pain (1), discovery of brain metastasis 1 week after start of treatment (1), and hyperbilirubinemia 1 week after start of treatment (1). These 5 inevaluable patients died between 0.5 and 8 months after start of treatment.

Responses are shown in Table 2. No complete responses were observed. A partial response (PR) was achieved in 4 out of 28 patients (14\%) with a median duration of 34 weeks (range 18-67+ weeks), while 8 patients ( $29 \%$ ) showed stable disease (SD) with a median duration of 28 weeks

Table 1. Patient characteristics

\begin{tabular}{lc}
\hline Number of patients entered: & 33 \\
Number of evaluable patients: & 28 \\
Menopausal status: & 1 \\
$\quad$ pre & 26 \\
post & 6 \\
$\quad$ peri or unknown & $57(40-74)$ \\
Age: & \\
$\quad$ median (range) & $1(0-2)$ \\
WHO performance status: & \\
median (range) & $3(1-4)$ \\
Metastatic sites per patient: & \\
\hline
\end{tabular}


(range $11^{+}-60$ weeks). One patient had early progressive disease after 2 weeks of treatment. Fifteen other patients showed tumor progression within 5 14 weeks after start of treatment. Progression-free survival and overall survival curves of the evaluable patients are shown in Fig. 1. Toxicity is presented in Table 3. Leukopenia grade II occurred in $48 \%$ and grade III in $15 \%$ of all cycles. Gastrointestinal toxicity was very mild. Serious hair loss grade II and III occurred in only a minority of the patients, and was probably still related to the previous $\mathrm{CMF}$ treatment.

In 10 of the 12 patients who achieved a PR or SD, LVEF was repeated at least once. Three patients received a 'doxorubicin equivalent' dose (cumulative doxorubicin dose+ cumulative mitoxantrone dose $\times 5$ ) of more than $550 \mathrm{mg} / \mathrm{m}^{2}$, i.e. 720 , 795 , and $850 \mathrm{mg} / \mathrm{m}^{2}$. LVEF of these patients dropped from 65 to $53 \%, 76$ to $61 \%$, and 80 to $73 \%$, respectively. $\mathrm{LVEF}$ of two other patients receiving a cumulative 'doxorubicin equivalent' dose of 195 and $292 \mathrm{mg} / \mathrm{m}^{2}$ dropped from 89 to $75 \%$ and from 76 to $64 \%$ respectively. In four other patients treated with 'doxorubicin equivalent' cumulative doses of 209 to $500 \mathrm{mg} / \mathrm{m}^{2}$, LVEF remained stable to the baseline value. Thus, in none of these 9 patients did LVEF decrease to below the critical limit of $50 \%$, and none of them showed any clinical sign of cardiotoxicity.

One patient, with previous mediastinal irradiation and pericarditis carcinomatosa, developed a cardiac failure in the presence of a drop in the absolute level of the LVEF from $78 \%$ to $29 \%$, after being treated with a 'doxorubicin equivalent' cumulative dose of $478 \mathrm{mg} / \mathrm{m}^{2}$. She was successfully treated with digoxin and diuretics.

Table 2. Type of responses and time to progression (WHO criteria)

\begin{tabular}{lll}
\hline & $\begin{array}{l}\text { Number of patients } \\
(\%)\end{array}$ & $\begin{array}{l}\text { Mean duration in weeks } \\
(\text { range })\end{array}$ \\
\hline CR & 0 & - \\
PR & $4(14)$ & $34\left(18-67^{+}\right)$ \\
SD & $8(29)$ & $28(11+-60)$ \\
PD & $16(57)$ & within 2-14 weeks \\
\hline
\end{tabular}

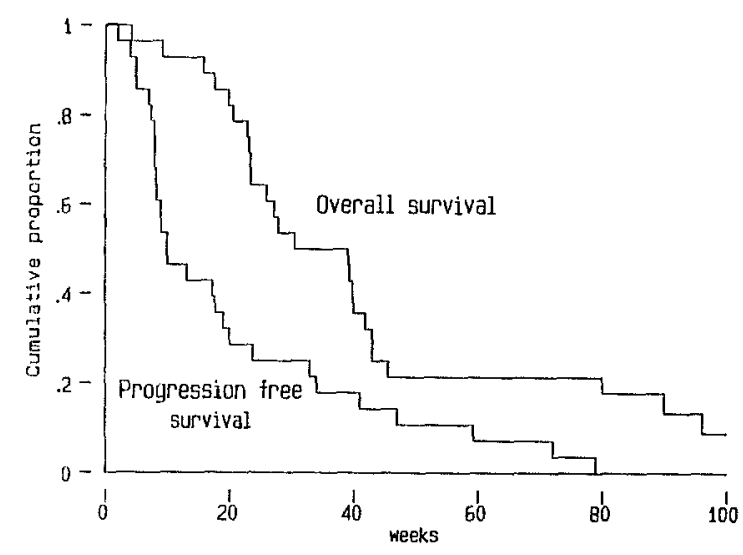

Fig. 1. Progression-free and overall survival of all evaluable patients measured in weeks from start of treatment.

\section{Discussion}

Several studies have shown that chemotherapy with weekly low doses of (4'-epi-)doxorubicin or mitoxantrone can be as effective as the 3-weekly high-dose schedules in inducing remissions in patients with advanced breast cancer, whereas toxicity of the low doses is considerable less [5-22, 27, 28]. Treatment results of 18 studies using 'weekly' low dose (4'-epi-)doxorubicin or mitoxantrone in patients with advanced breast cancer are shown in Tables 4 and 5 . Table 4 summarizes the treatment results of 7 studies concerning a total of 311 patients of whom less than $50 \%$ had been treated before with chemotherapy for advanced disease. Overall, 93 of the 311 patients (30\%) treated with weekly low-dose anthracycline or mitoxantrone

Table 3. Percentage of side effects (WHO grading)

\begin{tabular}{lrrrr}
\hline Grade & 0 & 1 & 2 & 3 \\
\hline Leukopenia* & 15 & 22 & 48 & 15 \\
Thrombocytopenia* & 80 & 9 & 9 & 2 \\
Mucositis* & 96 & 4 & - & - \\
Diarrhea* & 94 & 6 & - & - \\
Nausea/Vomiting* & 84 & 11 & 5 & - \\
Alopecia** & $82 \%$ & & $18 \%$ \\
*Percentage of courses with side effect events as recorded in all \\
(100\%) weekly chemotherapy courses. \\
$* *$ Alopecia is expressed as the percentage of patients experiencing \\
various grades (0/l and 2/3) of hair loss.
\end{tabular}


Table 4. Low-dose doxorubicin (Dox), 4'-epi-doxorubicin (Epi-dox), or mitoxantrone (Novantrone) mainly used as first-line chemotherapy in advanced breast cancer

\begin{tabular}{|c|c|c|c|c|c|c|c|}
\hline \multirow[t]{2}{*}{ Drug } & \multirow[t]{2}{*}{ Dosage } & \multirow{2}{*}{$\begin{array}{l}\text { Treatment interval } \\
\text { (weeks) }\end{array}$} & \multirow{2}{*}{$\begin{array}{l}\text { Number of eval. } \\
\text { pts }\end{array}$} & \multicolumn{2}{|c|}{ Responses (CR/PR) } & \multirow{2}{*}{$\begin{array}{l}\text { Prior chemother. } \\
(\% \text { pts) }\end{array}$} & \multirow[t]{2}{*}{ Ref. } \\
\hline & & & & (n) & $(\%)$ & & \\
\hline Dox & 15 or $20 \mathrm{mg}$ & 1 & 50 & 7 & 14 & 44 & (5) \\
\hline Dox & $20 \mathrm{mg}$ & 1 & 62 & 19 & 31 & 0 & (6) \\
\hline \multicolumn{8}{|l|}{ vs } \\
\hline VAC & & 3 & 66 & 24 & 35 & & \\
\hline Dox & $20 \mathrm{mg}$ & 1 & 81 & 29 & 36 & 0 & (7) \\
\hline \multicolumn{8}{|l|}{ vs } \\
\hline Epi-dox & $50 \mathrm{mg}$ & 2 & 68 & 15 & 22 & & \\
\hline Epi-dox & $12 \mathrm{mg} / \mathrm{m}^{2}$ & 1 & 42 & 18 & 43 & 12 & (8) \\
\hline Epi-dox & 20 or $40 \mathrm{mg}$ & 1 & 25 & 12 & 48 & $<24$ & (9) \\
\hline Epi-dox & $20 \mathrm{mg}$ & 1 & 41 & 4 & 10 & 17 & $(10)$ \\
\hline Novantrone & $3.3-6 \mathrm{mg} / \mathrm{m}^{2}$ & 1 & 10 & 4 & 40 & 0 & (11) \\
\hline
\end{tabular}

Number of eval. patients: 311 .

Number of patients achieving CR/PR: $93 / 311(30 \%)$.

Mean \% CR/PR of all 7 individual series: $32 \%$ (range $10-48 \%$ ).

responded objectively. The mean percentage of response of the 7 separate series of patients was $32 \%$ (range 10-48\%). Table 5 shows the treatment results of 11 studies concerning 361 patients of whom more than $50 \%$ had been pretreated with various types of chemotherapy. During this second-line chemotherapy 110 out of 361 patients (30\%) re- sponded. The mean percentage of response of the individual series was 29\% (range 0-59\%). Response durations in the studies vary widely. Based on response data available in 12 of these 18 studies, the median duration of response is about 6-7 months.

In our study we combined mitoxantrone and

Table 5. Low-dose doxorubicin (Dox) or 4'-epi-doxorubicin (Epi-dox) mainly used as second-line chemotherapy in advanced breast cancer

\begin{tabular}{|c|c|c|c|c|c|c|c|}
\hline \multirow[t]{2}{*}{ Drug } & \multirow[t]{2}{*}{ Dosage } & \multirow{2}{*}{$\begin{array}{l}\text { Treatment interval } \\
\text { (weeks) }\end{array}$} & \multirow[t]{2}{*}{ Number of eval. pts } & \multicolumn{2}{|c|}{ Responses (CR/PR) } & \multirow{2}{*}{$\begin{array}{l}\text { Prior chemother. } \\
\text { (\% pts) }\end{array}$} & \multirow[t]{2}{*}{ Ref: } \\
\hline & & & & (n) & $(\%)$ & & \\
\hline Dox & $0.4 \mathrm{mg} / \mathrm{kg}^{*}$ & 1 & 29 & 11 & 38 & 100 & (12) \\
\hline Dox & $0.5-1 \mathrm{mg} / \mathrm{kg}$ & 1 & 31 & 11 & 35 & heavily pretreated & (13) \\
\hline Dox & $20 \mathrm{mg} / \mathrm{m}^{2}$ & $1,3,1,3$ & 60 & 16 & 27 & 87 & (14) \\
\hline Dox & $6-12 \mathrm{mg} / \mathrm{m}^{2}$ & 1 & 34 & 20 & 59 & $>62$ & (15) \\
\hline Dox & $5-11.5 \mathrm{mg} / \mathrm{m}^{2}$ & 1 & 20 & 3 & 15 & 100 & (16) \\
\hline Dox & $8-12 \mathrm{mg} / \mathrm{m}^{2}$ & 1 & 17 & 2 & 12 & 70 & $(17)$ \\
\hline Dox & $10 \mathrm{mg} / \mathrm{m}^{2}$ & 1 & 24 & 0 & 0 & $>96$ & (18) \\
\hline Dox & $12 \mathrm{mg} / \mathrm{m}^{2}$ & 1 & 30 & 8 & 27 & 97 & (19) \\
\hline Dox & $20 \mathrm{mg}$ & 1 & 48 & 9 & 19 & 56 & $(20)$ \\
\hline Epi-dox & $20 \mathrm{mg}$ & 1 & 39 & 20 & 51 & 51 & (21) \\
\hline Epi-dox & $15 \mathrm{mg} / \mathrm{m}^{2}$ & 1 & 29 & 10 & 34 & 52 & (22) \\
\hline
\end{tabular}

Number of eval. patients: 361 .

Number of patients achieving CR/PR: 110/361 (30\%).

Mean \% CR/PR of all 11 individual series: $29 \%$ (range $0-59 \%$ ).

* Therapy with initial loading course (days $1-3$ and $8-10$ ). 
doxorubicin in weekly low-dose schedules in order to achieve a low toxicity profile with preserved activity. Subjective side effects, gastrointestinal toxicity, and alopecia were mild with this combination therapy, but leukopenia regularly needed postponement of the chemotherapy. In spite of these clear toxic effects on bone marrow function, the combination of weekly low-dose mitoxantrone and doxorubicin showed 'moderate' antitumor activity (14\% PR) as second-line chemotherapy in patients with metastatic breast cancer. However, in an additional $29 \%$ of the patients a SD was observed for $11^{+}-60$ weeks with nearly the same median duration of progression-free survival as for partial responders ( 28 vs 34 weeks). This median duration of SD (about 6-7 months) in our patients is not different from that of the objective responders reported in the other studies (Table 4 and 5), i.e. 6-7 months. The overall response rate (CR/PR/SD) of $43 \%$ also is generally not different from that reported in other studies, even in comparison with high-dose mitoxantrone 3-weekly in the first-line (40\%) as reported by Harris et al. [29].

Striking in our study was the clear dose-limiting bone marrow depression in spite of the low dosages of the drugs used. However, it has to be noted that the relatively high incidence of leukopenia compared to 3-weekly schedules is influenced by the frequent weekly measurement of $\mathrm{WBC}$ in this weekly dose regimen.

In vitro studies with the combination of both drugs had suggested a possible protective effect of mitoxantrone towards doxorubicin-induced cardiotoxicity [26]. This possible protective effect of mitoxantrone towards doxorubicin-induced cardiotoxicity, however, was not observed in two clinical studies that combined the drugs in 3-weekly 'high-dose' schedules [30, 31]. From our study we cannot make definite conclusions in this respect. Although 4 patients showed a significant relative decrease (16-20\% of the pretreatment value) of LVEF, none of them decreased below an absolute value of $50 \%$ with the exception of the patient with previous mediastinal irradiation and carcinomatous pericarditis.

It can be concluded that second-line combination treatment of weekly low-dose mitoxantrone plus doxorubicin is a well tolerated drug regimen for patients with CMF-resistant tumors. The antitumor efficacy is comparable to that of other second-line chemotherapeutic regimens in the $a b$ sence of serious side effects, but postponement of drug administration was regularly needed because of the occurrence of leukopenia.

\section{Acknowledgements}

We wish to thank P.J. van Assendelft and J. Vuik for preparing the print, and DG Lederle Netherlands for support.

\section{References}

1. Henderson IC, Harris JR, Kinne DW, Hellman S: Cancer of the breast. In: DeVita VT, Hellman S, Rosenburg SA (eds) Cancer, Principles and Practice of Oncology, Lippincott, Philadelphia 1989, pp 1197-1268

2. Cersosimo RJ, Hong WK: Epirubicin: a review of the pharmacology, clinical activity, and adverse effects of an adriamycin analogue. J Clin Oncol 4: 425-439, 1986

3. Neidhart JA, Gochnour D, Roach R, Hoth D, Young D: A comparison of mitoxantrone and doxorubicin in breast cancer. J Clin Oncol 4: 672-677, 1986

4. Henderson IG, Allegra JC, Woodcock T, Wolff S, Bryan S, Cartwright K, Dukart G. Henry D: Randomized clinical trial comparing mitoxantrone with doxorubicin in previously treated patients with metastatic breast cancer. J Clin Oncol 7: 560-571, 1989

5. Nylen U, Baral E, Svane G, Rutqvist LE: Weekly doxorubicin in the treatment of breast cancer. Acta Oncol 28: 515-517, 1989

6. Gundersen S, Kvinnsland S, Klepp O, Lund E, Host H: Weekly adriamycin versus $V A C$ in advanced breast cancer. A randomized trial. Eur J Cancer Clin Oncol 22: 1431-1434, 1986

7. Gundersen S, Kvinnsland S, Klepp O, Lund E, Host H: Weekly Adriamycin vs. 4-epidoxorubicin every second week in advanced breast cancer. A randomized trial. Eur $\mathbf{J}$ Cancer Clin On$\operatorname{col} 26: 45-48,1990$

8. Jones WG, Mattson W: Phase II study of weekly low-dose 4'-epidoxorubicin in advanced postmenopausal breast cancer. Cancer Treat Rep 68: 675-677, 1984

9. Ebbs SR, Saunders JA, Graham H, A'Hern RP, Bates T, Baum M: Advanced breast cancer. A randomised trial of epidoxorubicin at two different dosages and two administration systems. Acta Oncol 28: 887-892, 1989

10. Dixon AR, Robertson JFR, Athanassiou E, Jackson L, Blamey RW: Weekly low dose epirubicin in advanced breast cancer. Eur $\mathrm{J}$ Cancer Clin Oncol 26: 847-848, 1990

11. Blijham GH, Wals J, Bron H, Wils J, van Deijk G, Hupperets P, 
Schouton L: Weekly mitoxantrone as first-line chemotherapy: A dose-intensity study in elderly patients with metastatic breast cancer (Abstract). Proc. 4th EORTC Breast Cancer Working Conference, London, F2.27, 1987

12. Weiss AT, Metter GE, Fletcher WS, Wilson WL, Crage TB, Ramirez G: Studies on adriamycin using a weekly regimen demonstrating its clinical effectiveness and lack of cardiac toxicity. Cancer Treat Rep 60: 813-822, 1976

13. Chlebowski RT, Paroly WS, Pugh RP, Hueser J, Jacobs EM, Pajak TF, Bateman JR: Adriamycin given as a weekly schedule without a loading course: clinically effective with reduced incidence of cardiotoxicity. Cancer Treat Rep 64: 47-51, 1980

14. Creech RH, Catalano RB, Shah MK: An effective low-dose Adriamycin regimen as secondary chemotherapy for metastatic breast cancer patients. Cancer 46: 433-437, 1980

15. Mattsson W, Borgstrom S, Landberg T: A weekly schedule of low dose doxorubicin in treatment of advanced breast cancer. Clin Ther 5: 193-201, 1982

16. Kessinger A, Lemon HM, Foley JF: Mini-dose weekly Adriamycin therapy for patients with advanced malignant disease at increased risk for adriamycin toxicity. Am J Clin Oncol 6: 113-115, 1983

17. Scheithauer W, Zielinski C, Ludwig H: Weekly low dose doxorubicin monotherapy in metastatic cancer resistant to previous hormonal and cytostatic breast treatment. Breast Cancer Res Treat 6: 89-93, 1985

18. Specenier P, Thomas J: Weekly low-dose doxorubicin in advanced breast cancer. Cancer Treat Rep 70: 815, 1986

19. Namer M, Khater R, Boublil JL, Thyss A, Bourry J: L'adrimycine à faible dose hebdomaire, dernière thérapeutique du cancer đu sein avancé. La Presse Médicale 15: 1315-1317, 1986

20. Sigurdsson H, Johansson-Terje I, Aspegren K, Landberg T, Andersson T, Borgstrom S, Thelin A-M: Weekly-dose doxorubicin (WDA) in advanced breast cancer. Radiother Oncol 7: 133-139, 1986

21. Jones WG: Effective palliation of advanced breast cancer with weekly low dose epirubicin. Eur J Cancer Clin Oncol 25: 357369,1989

22. Tucci E, Algeri R, Guarnieri A, Pepi F, Sapio L, Bastreghi G, Pirtoli L: Weekly epirubicin in advanced breast cancer. Tumori 74: 689-692, 1988

23. Meyers CE, McGuire WP, Liss RA, Ifrim I, Grotzinger K, Young $\mathrm{RC}$ : Adriamycin: the role of lipid peroxidation in cardiotoxicity and tumor response. Science 197: 165-167, 1977

24. Mimnaugh EG, Trush MA, Ginburg E, Gram T: Differential effects of anthracycline drugs on rat heart and liver microsomal reduced nicotinamide adenine dinucleotide phosphate-dependent lipid peroxidation. Cancer Res 42: 3574-3582, 1982

25. Doroshow JH, Davies KJA: Comparative cardiac oxygen radical metabolism by anthracycline antibiotics, mitoxantrone, bisantrene, 4'-(9-acridinylamino)-methanesulfon-m-anisidine, and neocarzinostatin. Biochem Pharmacol 32: 2935-2939, 1983

26. Kharasch ED, Novak RF: Inhibition of adriamycin stimulated microsomal lipid peroxidation by mitoxantrone and ametantrone, two new anthracenedione antineoplastic agents. Biochem Biophys Res Commun 108: 1346-1352, 1982

27. Torti FM, Britow MR, Howes AE, Aston D, Stockdale FE, Carter SK, Kohler M, Brown BW, Billingham ME; Reduced cardiotoxicity of doxorubicin delivered on a weekly schedule: assessment by endomyocardial biopsy. Ann Intern Med 99: 745-749, 1983

28. Von Hoff D, Layard MW, Basa P, Davis HL, Von Hoff AL, Rozencweig M, Muggia FM: Risk factors for doxorubicin-induced congestive heart failure. Ann Intern Med 91: 710-717, 1979

29. Harris AL, Cantwell BMJ, Carmichael J, Wilson R, Farndon J, Dawes P, Ghani S, Evans RGB: Comparison of short-term and continuous chemotherapy (mitozantrone) for advanced breast cancer. The Lancet 335: 186-190, 1990

30. Ford JM, Panasci L, Leclerc Y, Margolese R: Phase II trial of a combination of doxorubicin and mitoxantrone in metastatic breast cancer. Cancer Treat Rep 71: 921-925, 1987

31. Stewart DJ, Perrault DJ, Maroun JA, Lefevbre BM: Combined mitoxantrone plus doxorubicin in the treatment of breast cancer. Am J Clin Oncol 10: 335-340, 1987 